\title{
Neurosteroid Modulation of Ionotropic Glutamate Receptors and Excitatory Synaptic Transmission
}

\author{
M. SEDLÁČEK ${ }^{1}$, M. KOŘÍNEK ${ }^{1}$, M. PETROVIČ ${ }^{1}$, O. CAIS $^{1}$, E. ADAMUSOVÁ $^{\mathbf{1}}$, \\ H. CHODOUNSKÁ ${ }^{2}$, L. VYKLICKÝ Jr. ${ }^{1}$
}

${ }^{1}$ Institute of Physiology, Academy of Sciences of the Czech Republic, v.v.i., and ${ }^{2}$ Institute of Organic Chemistry and Biochemistry, v.v.i., Prague, Czech Republic

Received February 15, 2008

Accepted April 16, 2008

On-line May 13, 2008

\section{Summary}

Ionotropic glutamate receptors function can be affected by neurosteroids, both positively and negatively. N-methyl-Daspartate (NMDA) receptor responses to exogenously applied glutamate are potentiated or inhibited (depending on the receptor subunit composition) by pregnenolone sulphate (PS) and inhibited by pregnanolone sulphate (3a5BS). While PS effect is most pronounced when its application precedes that of glutamate, 3a5BS only binds to receptors already activated. Synaptically activated NMDA receptors are inhibited by $3 a 5 \beta S$, though to a lesser extent than those tonically activated by exogenous glutamate. PS, on the other hand, shows virtually no effect on any of the models of synaptically activated NMDA receptors. The site of neurosteroid action at the receptor molecule has not yet been identified, however, the experiments indicate that there are at least two distinct extracellularly located binding sites for PS mediating its potentiating and inhibitory effects respectively. Experiments with chimeric receptors revealed the importance of the extracellular loop connecting the third and the fourth transmembrane domain of the receptor NR2 subunit for the neurosteroid action. a-amino-3-hydroxy-5-methyl4-isoxazolepropionate (AMPA)/kainate receptors are inhibited by both PS and 3a5BS. These neurosteroids also affect AMPA receptors-mediated synaptic transmission, however, in a rather indirect way, through presynaptically located targets of action.

\section{Key words}

$\mathrm{N}$-methyl-D-aspartate receptor $\bullet$ AMPA receptor $\bullet$ Glutamate receptor $\bullet$ EPSC $\bullet$ Neurosteroid $\bullet$ Allosteric modulation

\section{Corresponding author}

L. Vyklický Jr., Institute of Physiology AS CR v.v.i., Vídeňská 1083, 14220 Prague 4, Czech Republic. Fax: (420) 241062488. E-mail: vyklicky@biomed.cas.cz

\section{Introduction}

Steroid hormones can easily cross the bloodbrain barrier and function at the genomic level to produce changes in mood and behavior. These effects occur relatively slowly (taking from minutes to hours) (McEwen 1991). In addition, certain steroids can produce immediate changes (within seconds or even milliseconds) in neuronal excitability, which suggests a different way of functioning. Even though this rapid effect of these neuroactive compounds was observed more than half a century ago (Selye 1941), the molecular mechanism of their action remained unknown for a long time. It was only in the 1980s that the first study on the effects of steroids on $\mathrm{GABA}_{\mathrm{A}}$ receptors appeared (Harrison and Simmonds 1984), followed by works on modulation of the other types of ligand-gated ion channels such as glutamate, glycine or nicotinic acetylcholine receptors (Wu et al. 1990, 1991, Bullock et al. 1997); for review see (Rupprecht and Holsboer 1999). At about the same time it was shown that the neuroactive steroids are synthesized directly in the nervous tissue (Corpechot et al. 1981), hence the term neurosteroids. Evidence has been provided for synthesis de novo from cholesterol or in situ from steroidal precursors imported from peripheral sources (Baulieu 1998).

The modulatory effect of neurosteroids on the activity of ligand-gated ion channels was suggested to play a role in a range of physiological processes such as learning, aging and stress as well as certain 


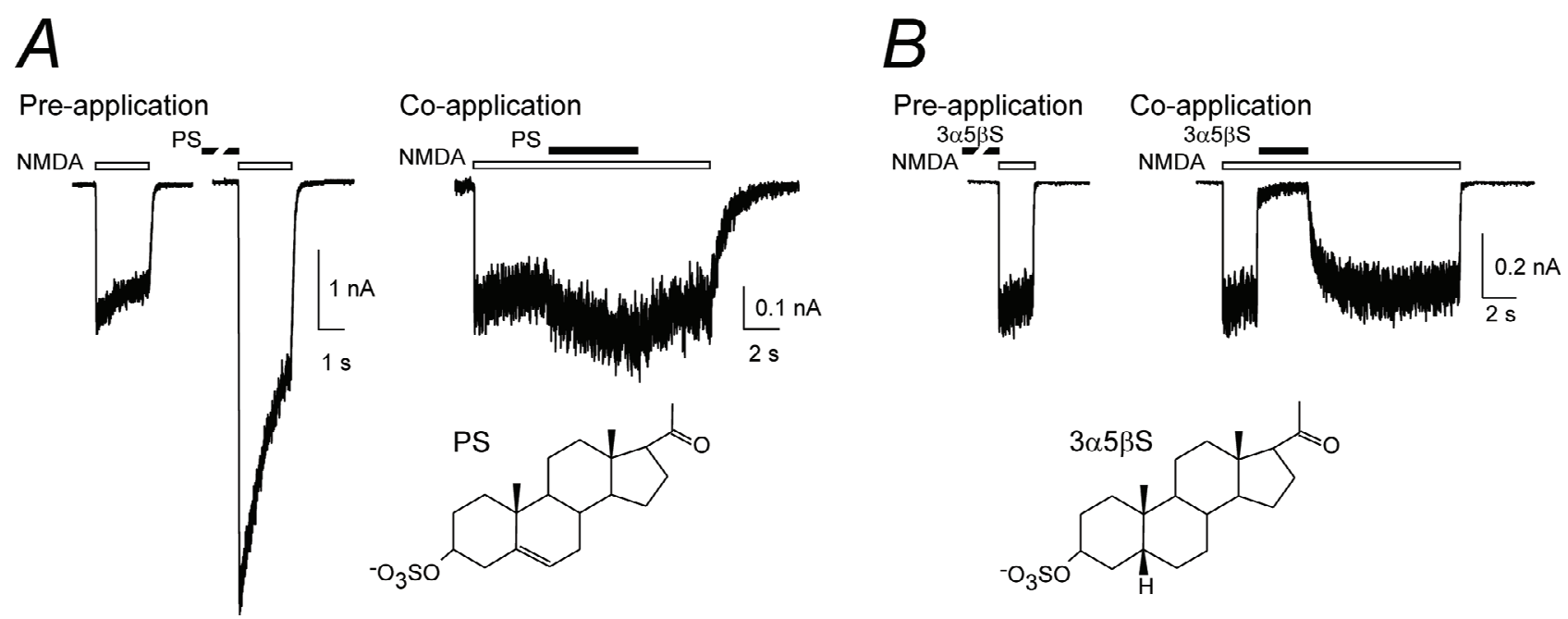

Fig. 1. Disuse-dependent and use-dependent effect of neurosteroids on NMDA receptor activity. (A) Effects of PS on NR1-1a/NR2B NMDA receptors expressed in HEK cells. Pre-application of PS $(300 \mu \mathrm{M})$ produces several-fold increase in responses evoked by NMDA $(100 \mu \mathrm{M})$. Simultaneous application of PS $(100 \mu \mathrm{M})$ and the agonist produces little effect. Inset shows structure of pregnenolone sulfate (PS). B) Effects of $3 a 5 \beta S(300 \mu M)$ on NR1-1a/NR2B NMDA receptors expressed in HEK cells. Pre-application of $300 \mu M 3 a 5 \beta S$ produces no effect on the time-course and amplitude of the subsequent response to NMDA $(100 \mu \mathrm{M})$. Simultaneous co-application of NMDA $(100 \mu \mathrm{M})$ and $3 \mathrm{a} 5 \beta \mathrm{S}$ produces almost complete inhibition. Inset shows structure of pregnanolone sulfate (3a5ßS).

neuropsychiatric disorders (Flood and Roberts 1988, Nasman et al. 1991, Grobin et al. 1992, Vallee et al. 1997); for review see (Gasior et al. 1999). Therefore, full understanding of the biochemical pathways, mechanisms of function and receptor binding sites of these compounds can be crucial for new drug design and therapeutic procedures.

The mechanism of neurosteroid action at $\mathrm{GABA}_{\mathrm{A}}$ receptors was reviewed recently (Belelli et al. 2006, Herd et al. 2007, Hosie et al. 2007, Morrow 2007). The aim of this review is to summarize current knowledge of the molecular mechanism of the effect of neurosteroids on NMDA and AMPA/kainate receptors and the synaptic transmission mediated by these receptors.

\section{Neurosteroid modulation of NMDA recep- tors}

Molecular mechanism of neurosteroid action with positive allosteric effect

The first observation of a neurosteroid action on NMDA receptors was published by (Wu et al. 1991). Cell-cultured chick spinal cord neurons exhibited a more than $200 \%$ increase of response to NMDA when $300 \mu \mathrm{M}$ pregnenolone sulfate (PS) was present before and during the NMDA application. This finding was later confirmed by numerous studies of cells with native as well as recombinant NMDA receptors (Bowlby 1993, Park-
Chung et al. 1997, Ceccon et al. 2001, Malayev et al. 2002, Horak et al. 2004).

Several studies aimed to find the functional group of PS responsible for potentiation. Unlike the strong potentiating effect of PS, pregnenolone does not affect NMDA receptor responses (Weaver et al. 2000). Thus, the sulfate group at carbon $\mathrm{C} 3$ is important for the potentiating effect (Fig. 1A). However, the potentiating effect is maintained if the sulfate group is replaced by another negatively charged group, e.g. hemioxalate, hemisuccinate or hemiglutarate (Park-Chung et al. 1997, Weaver et al. 2000). The double bond between C5 and C6 is also of essential importance. Its absence, accompanied by $5 \beta$ arrangement of chiral $\mathrm{C} 5$ in pregnanolon sulfate $(3 \alpha 5 \beta S)$, changes the shape of the neurosteroid molecule (Fig. 1A). While the PS molecule is roughly planar, the $3 \alpha 5 \beta \mathrm{S}$ molecule has a hooked shape, which results in the complete reversal of the potentiating effect, making $3 \alpha 5 \beta S$ a strong inhibitor of NMDA receptors (Park-Chung et al. 1994, Weaver et al. 2000, Petrovic et al. 2005). The effect of neurosteroids with a potentiating and inhibitory effect seems to be mediated by independent binding sites located at the extracellular domain of the NMDA receptor (Park-Chung et al. 1997, Horak et al. 2006).

To say that NMDA receptors are potentiated by PS is to simplify a more complex phenomenon. Electrophysiological measurements of recombinant NMDA receptors expressed in Xenopus laevis oocytes and 
HEK-293 cells revealed that receptors containing NR1/NR2A and NR1/NR2B subunits are potentiated by PS, whereas NR1/NR2C and NR1/NR2D receptors are inhibited by PS (Ceccon et al. 2001, Malayev et al. 2002, Horak et al. 2004, Horak et al. 2006). This fact was utilized to localize the amino-acid region which is crucial for PS potentiation (Jang et al. 2004, Horak et al. 2006). Chimeras of NR2 subunits assembled from fragments of NR2A or NR2B (potentiated by PS) and NR2C or NR2D subunits (less affected by PS) were used to infer the subunit domain important for PS action at NMDA receptors. The studies from both laboratories indicate the importance of the extracellular loop spanning the third and fourth transmembrane domains and the fourth transmembrane domain for the potentiating effect of PS. (Jang et al. 2004) further focused on point mutations of amino acid residues within this region. Surprisingly, out of 15 mutated NR2B subunits only the substitution of NR2B glutamine by NR2D lysine at residue 812 significantly reduced the response to PS. This residue may be directly involved in PS binding; however, other explanations must be considered. The results of experiments of (Horak et al. 2006) show that the low degree of PS-induced potentiation of receptors containing NR2C-D subunits resides in low efficacy rather than low PS affinity (which is actually higher for these subunits). This indicates that the M3-M4 loop may be involved only in signal transduction rather than in direct PS binding. High-resolution crystal structure data and further mutagenesis studies are necessary to identify the PS binding site at the NMDA receptor.

Exploration of the molecular mechanisms responsible for the potentiating effect of PS indicates that this neurosteroid increases the probability of NMDA receptor channel opening. At a saturating concentration of PS it results in approximately 4-fold potentiation of responses of receptors composed of NR1/NR2A and NR1/NR2B subunit combinations (Horak et al. 2004, Horak et al. 2006). Surprisingly, the effect of PS is robust when it is pre-applied before the agonist but much weaker if the PS is co-applied with the agonist (Fig. 1A) (Horak et al. 2004). The results of electrophysiological experiments indicate that this is due to an allosteric coupling of glutamate and PS binding sites, resulting in a decrease in the affinity of the receptor to PS after agonistinduced activation.

Not only does PS potentiate NMDA (NR1/NR2A and NR1/NR2B) receptor response to the agonist but it also exhibits a weaker inhibitory effect, which is usually masked by much stronger potentiation
(Horak et al. 2004, Horak et al. 2006). The inhibitory effect becomes apparent, for instance, in experiments when the solution with PS is swiftly washed away from the cultured cells. Instead of the gradual decrease of the current conducted by the ion channels, the current first rises temporarily and then it falls. The temporary rise is due to the faster unbinding of PS from the inhibitory binding site, allowing the receptors to be fully potentiated until PS also unbinds from the potentiating binding site. The ability of PS to bind simultaneously to potentiating and inhibitory binding sites was observed in the NMDA receptors of all subunit compositions (Horak et al. 2006). The overall effect of PS (potentiation of NR1/NR2A and $\mathrm{NR} 1 / \mathrm{NR} 2 \mathrm{~B}$, inhibition of NR1/NR2C and NR1/NR2D) is the result of different affinities of PS towards these binding sites and the subunit-dependent efficiency of potentiation/inhibition from these binding sites. Simultaneous occupation of potentiating and inhibitory binding sites was also reported in the case of neurosteroid modulation of GABA receptors (Park-Chung et al. 1999).

Recently, it has been reported that PS affects NMDA receptors even at nanomolar concentrations. (Johansson et al. 2008) studied the binding of ifenprodil (the specific inhibitor of NR2B subunit) to NR1/NR2B receptors. They found that at nanomolar concentrations, PS does not alter the response to glutamate but influences the extent of ifenprodil inhibition of the receptor. This is therefore probably another phenomenon, which is distinct from the potentiating and inhibitory phenomena of PS described above (Johansson et al. 2008).

Pregnenolone sulfate action on synaptically activated NMDA receptors

Surprisingly, although PS has a strong potentiating effect on recombinant and native (extrasynaptic) receptors activated by exogenous agonist application, it produces virtually no effect on the amplitude of excitatory postsynaptic currents mediated by NMDA receptors (NMDA receptor-mediated EPSCs) in hippocampus (Partridge and Valenzuela 2001), dentate gyrus (Chen and Sokabe 2005), spinal cord (Abdrachmanova et al. 2001) and cultured hippocampal neurons (Meyer et al. 2002). The reason for this is not clear, but possible explanations are site-specific differences in subunit composition, a developmental switch in subunit gene expression, an association with various sets of sub-membrane proteins or a regulatory change in receptor function - for example, by phosphorylation as the universal process. Some of these 
possibilities are discussed below.

It has been recently reported that in the hippocampal dentate gyrus of adult rats, the effect of PS on synaptic responses depends not only on the direct action of PS on NMDA receptors, but also on the activation of tyrosine kinases in the postsynaptic cell (Chen et al. 2007) - more specifically, on src-kinases, which, by themselves, are important activators of NMDA receptor activity (Salter and Kalia 2004). One possible mechanism for achieving this PS action could involve the activation of src-kinases in a round-about manner, through activation of sigma- 1 receptors, similar to what has been shown for the effect of dehydroepiandrosterone sulfate, another neurosteroid that activates src-kinases through the activation of sigma-1 receptor (Chen et al. 2006, Li et al. 2006).

In addition, PS action is not necessarily limited to the postsynaptic cell but could involve the presynaptic terminal as well. PS facilitates both evoked and spontaneous glutamate release in cultured neonatal hippocampal neurons. This can be concluded from the effects of PS on changes in neurotransmitter release, which is represented by paired-pulse facilitation and/or change in frequency of miniature EPSCs (Meyer et al. 2002). On the other hand, opposite results were obtained when the studies with PS were performed on hippocampal neurons from adult animals (Partridge and Valenzuela 2001).

These findings can be reconciled by assuming that PS acts via presynaptic NMDA receptors, but that the developmental switch in the subunit type changes the overall probability of glutamate release (Mameli et al. 2005). Similar age-dependency exists in the rat calyx of Held, because in younger animals (postnatal day 7-9), PS applied at a concentration of $100 \mu \mathrm{M}$ increases the frequency of miniature EPSCs and strongly potentiates evoked EPSCs. The latter effect becomes inconsistent, sometimes even inhibitory, on older (postnatal day 13) animals. In addition, it was found that the presynaptic effect of PS in this model is mediated by still another type of channel, namely, by activation of voltage-gated calcium channels (Hige et al. 2006). Importantly, it was found that the intracellular downstream signal transduction pathways appear to involve adenylyl cyclase and protein kinase $\mathrm{A}$ on the one hand and release of calcium from intracellular stores coupled to activation of protein kinase $C$ on the other (Dong et al. 2005). This, however, does not seem to be the universal mechanism, because in the calyx of Held (Hige et al. 2006), the PS effect depended on neither of these protein kinases (PKA and $\mathrm{PKC}$ ). Also, different findings come from the hippocampus, where PS action was dependent exclusively on extracellular calcium (Meyer et al. 2002).

Adding to the complexity is the possibility that it is not only receptors themselves that need to be phosphorylated, but that the phosphorylation of other proteins associated with them in the synapse can also influence the activity of the whole complex, as is the case for $\mathrm{GABA}_{\mathrm{A}}$ receptors (Kannenberg et al. 1997).

\section{Molecular mechanism of neurosteroid action with negative allosteric effect}

Pregnanolone sulfate $(3 \alpha 5 \beta S)$ is a neurosteroid naturally occurring in the mammalian central nervous system. In contrast to PS, it has an inhibitory effect on responses mediated by NMDA receptors (Park-Chung et al. 1994). It differs from pregnenolone sulfate (PS) by just a single unsaturated bond (Fig. 1B). Sulfate moiety has been shown to be essential for the neurosteroid efficacy since unsulfated derivative ( $3 \alpha 5 \beta$ has no effect on responses mediated by NMDA receptors (Park-Chung et al. 1994). Several lines of evidence indicate that the action of $3 \alpha 5 \beta S$ on NMDA receptors is noncompetitive and that it acts through a site distinct from the NMDA recognition site (Park-Chung et al. 1994).

The binding of $3 \alpha 5 \beta S$ to its sites at the NMDA receptors is strongly dependent on receptor activation the neurosteroid binds and unbinds in the presence of NMDA receptor channel agonists (NMDA or glutamate) while in the absence of these agonists the neurosteroid is unable to bind to the receptor (Fig. 1B) (Petrovic et al. 2005). This use-dependency is typical also for another group of compounds - the NMDA receptor channel blockers such as $\mathrm{Mg}^{2+}$, ketamine, memantine and MK801 , - which, in contrast to $3 \alpha 5 \beta S$, exhibit a voltagedependent block of NMDA receptor channels (ParkChung et al. 1994, Abdrachmanova et al. 2001). This difference strongly suggests that the $3 \alpha 5 \beta \mathrm{S}$ binding site is located outside the ion channel pore and therefore must be different from the site of ion channel blockers.

Kinetic experiments were used to assess the molecular mechanisms by which $3 \alpha 5 \beta \mathrm{S}$ inhibits NMDA receptors. The results indicate that the main effect of $3 \alpha 5 \beta S$ is to reduce the probability of NMDA receptor ion channel opening. In addition, the results of single-channel analysis have shown that the relative degree of inhibition is similar to that observed on the whole-cell NMDA receptor responses. In the presence of neurosteroid, the frequency of 
single NMDA receptor channel openings was reduced and the mean open time of NMDA receptor channel openings shortened. In contrast, no significant difference was observed in the distribution of NMDA receptor channel amplitudes. These results indicate that the neurosteroid mainly affects the rate constant of channel opening rather than of channel closing (Petrovic et al. 2005).

Single channel analysis of $3 \alpha 5 \beta$ S action on the NMDA receptor channel activity induced in outside-out patches isolated from spinal cord motoneurons revealed effects which were dependent on the single channel conductance. This indicates that the inhibitory action of the neurosteroid may depend on the receptor subunit composition (Abdrachmanova et al. 2001). The subunit preference of $3 \alpha 5 \beta \mathrm{S}$ action at NMDA receptors was confirmed by using recombinant receptors, showing that this neurosteroid has lower potency on receptors containing NR2A-B subunits than on those containing NR1/NR2C-D subunits. However, it is relatively independent of the type of NR1 subunit (Malayev et al. 2002, Petrovic et al. 2005). The experiments with chimeric NR2A-NR2C receptors indicate the importance of the M3-M4 loop of the NR2 subunit for the $3 \alpha 5 \beta S$ effect (Petrovic et al. 2005).

\section{$3 \alpha 5 \beta S$ action on synaptically activated NMDA receptors}

The effects of $3 \alpha 5 \beta \mathrm{S}$ on the NMDA receptormediated EPSCs were studied in motoneurons in spinal cord slices and neocortical layer II/III pyramidal neurons (Abdrachmanova et al. 2001, Petrovic et al. 2005). Surprisingly, despite the similar experimental approaches and species used, $3 \alpha 5 \beta \mathrm{S}(100 \mu \mathrm{M})$ had no effect on either the amplitude or the deactivation kinetics of NMDA receptor-mediated EPSCs recorded from spinal cord motoneurons (Abdrachmanova et al. 2001); however, it reduced the amplitude of NMDA receptor-mediated EPSCs recorded from neocortical layer II/III neurons (Petrovic et al. 2005). Several factors may account for the lower effect of $3 \alpha 5 \beta \mathrm{S}$ on NMDA receptors activated during synaptic transmission and those activated by exogenous agonist application. One of them may be related to the use-dependent action of $3 \alpha 5 \beta \mathrm{S}$. In the case of tonically activated NMDA receptors, $3 \alpha 5 \beta S$-induced inhibition will reach a steady-state within several seconds; however, the relatively slow rate constant of neurosteroid binding and its use-dependency indicate that during brief NMDA receptor activation the neurosteroid will not reach equilibrium. Therefore, it affects synaptic receptors that are phasically activated by glutamate less than those tonically activated by prolonged agonist activation. This mechanism was sufficient to explain the differences in the degree of $3 \alpha 5 \beta \mathrm{S}$-induced inhibition of NMDA receptors activated during synaptic transmission and those tonically activated in neocortical pyramidal neurons (Petrovic et al. 2005). At this stage, our knowledge of the mechanism of $3 \alpha 5 \beta \mathrm{S}$ action at synaptically activated NMDA receptors is limited. It is likely that some endogenous factors control the receptor sensitivity to the inhibitory neurosteroids. This may be the cause of the relative insensitivity of synaptic NMDA receptors to $3 \alpha 5 \beta S$.

\section{Neurosteroid modulation of AMPA/kainate receptors}

The neurosteroid modulation of AMPA ( $\alpha$ amino-3-hydroxy-5-methyl-4-isoxazolepropionate) and kainate receptors (two distinct subclasses of ionotropic glutamate receptors often grouped together as "nonNMDA") has been studied less intensively than the neurosteroid modulation of NMDA receptors but some common features, as well as differences, have nonetheless been discovered. The function of all subclasses of ionotropic glutamate receptors is affected by PS and $3 \alpha 5 \beta S$ but not by their nonsulfated analogues (Park-Chung et al. 1994, Shirakawa et al. 2005). However, unlike their effect on NMDA receptors, the effect of both PS and $3 \alpha 5 \beta S$ on AMPA/kainate receptors is inhibitory: $100 \mu \mathrm{M}$ PS inhibits the current responses of chick spinal cord neurons induced by AMPA and kainate by $29 \%$ and $25 \%$, respectively (Wu et al. 1991); similarly, $100 \mu \mathrm{M} 3 \alpha 5 \beta$ S causes $29 \%$ and $37 \%$ inhibition (Park-Chung et al. 1994, Shirakawa et al. 2005) as opposed to $70 \%$ inhibition of NMDAR responses (Petrovic et al. 2005). These findings were confirmed by utilizing recombinant AMPA (GluR1 or GluR3) and kainate (GluR6) receptors expressed in Xenopus oocytes (Yaghoubi et al. 1998). The dose-response curves in this study further demonstrated that PS reduces the AMPA/kainate receptor-mediated maximum current response to kainate application without affecting the $\mathrm{EC}_{50}$ of this agonist, indicating clearly that the mechanism of this neurosteroid action is noncompetitive. The independence of binding sites for glutamate and PS (or $3 \alpha 5 \beta S$ ) has also been reported in a study using intrinsic fluorescence spectroscopy to identify the neurosteroid binding site on the S1S2 domain of the GluR2 subunit (Spivak et al. 2004). 
Table 1. Summary of PS and 3a5ßS effects on NMDA receptors

\begin{tabular}{ccccc}
\hline Neurosteroid & Effect & Binding & $\begin{array}{c}\text { Subunit preference } \\
\text { action }\end{array}$ & $\begin{array}{c}\text { Effect on amplitude of } \\
\text { EPSC }\end{array}$ \\
\hline$P S$ & $\begin{array}{c}\text { Potentiating and } \\
\text { inhibitory } \\
3 \alpha 5 \beta S\end{array}$ & $\begin{array}{c}\text { Disuse- } \\
\text { dependent } \\
\text { Inhibitory }\end{array}$ & NR2A-B & No effect \\
\hline
\end{tabular}

The C-3 sulfate group of PS and $3 \alpha 5 \beta$ S can be replaced with a hemisuccinate group without losing the NMDA receptor-modulating abilities of the steroid (Weaver et al. 2000). Similarly, recombinant AMPA receptors (GluR1 and GluR3 homomers) are equally inhibited by PS and pregnenolone hemisuccinate (PHS) (Yaghoubi et al. 1998). On the other hand, kainate receptors (GluR6) are inhibited substantially less by PHS than by PS (15\% vs. $42 \%$ ) (Yaghoubi et al. 1998). Moreover, pregnenolone hemisuccinate was reported to have no significant effect on AMPA cytotoxicity in rat cortical slice cultures or AMPA-induced currents in cultured cortical neurons, whereas PS acted as an inhibitor in both cases (Park-Chung et al. 1994, Shirakawa et al. 2005). Therefore it seems that the presence of negatively charged group maintains the modulatory effect, however the effect is less pronounced.

Synaptic transmission mediated by AMPA receptors is also affected by sulfated steroids. The underlying mechanism of this action, however, seems to be indirect rather than directly influencing the properties of the receptors. PS application causes an increase in the frequency of AMPA receptor-mediated mEPSCs in cultured hippocampal neurons (Meyer et al. 2002), as well as in acute hippocampal slices of P3-4 rats (Mameli et al. 2005). However, the mEPSC amplitude is unaffected by PS in both cases, supporting the hypothesis that the site of the steroid action is presynaptic (as discussed in 2.2) - namely, the presynaptic NMDA receptors, since the effect of PS in the slices (though not in the cultivated neurons) is $\mathrm{Ca}^{2+}$ - and NMDA receptordependent. Moreover, in the slices, a delayed increase in evoked AMPA EPSCs amplitude has been reported (Mameli et al. 2005). This action is postsynaptically localized and again $\mathrm{Ca}^{2+}$ - and NMDA receptordependent. A model has been proposed in which this PSinduced enhancement of AMPA currents is caused by insertion of AMPA receptors in the postsynaptically silent synapses (Mameli et al. 2005); this resembles the well-established model of long-term potentiation.

\section{Conclusions}

In this review, we present a summary of the effects of two endogenous neurosteroids - pregnenolone sulfate and pregnanolone sulfate - on NMDA receptors. We show that structural and sterical differences between these two substances account for their radically different properties, as summarized in Table 1. Importantly, their action depends also on the timing of their application (relative to the application of the agonist). Still, results from transfected cells and cultured neurons significantly differ from those registered in vivo, when only synaptic receptors are activated. The reasons for this are still unclear, but present efforts in our laboratory are directed at solving this issue.

In recent years, we have witnessed a surge of interest in neurosteroids. Several lines of research emerge: defining the molecular mechanism of neurosteroid action on various ionotropic receptors, the cellular regulatory mechanisms of neurosteroid effects, an integrative approach to neurosteroid function in various systems within CNS and, most importantly, the possibility of the practical use of the above-mentioned findings in clinical setting. In vivo results are promising but the final goal is still very distant. Combined with the research in the pathophysiology of neurodegenerative diseases (and particularly the role of NMDA receptors in many of these), neurosteroids will hopefully bring new therapeutical options in the years to come.

\section{Conflict of Interest}

There is no conflict of interest.

\section{Acknowledgements}

This work was supported by the Grant Agency of the Czech Republic (309/07/0271; 203/08/1498, 309/08/H079), Research Project of the AS CR AV0Z 50110509, EC FP6 PHOTOLYSIS (LSHM-CT-2007037765) and Ministry of Education, Youth and Sports of the Czech Republic (1M0002375201 and LC554). 


\section{References}

ABDRACHMANOVA G, CHODOUNSKA H, VYKLICKY L Jr: Effects of steroids on NMDA receptors and excitatory synaptic transmission in neonatal motoneurons in rat spinal cord slices. Eur J Neurosci 14: 495-502, 2001.

BAULIEU EE: Neurosteroids: a novel function of the brain. Psychoneuroendocrinology 23: 963-987, 1998.

BELELLI D, HERD MB, MITCHELL EA, PEDEN DR, VARDY AW, GENTET L, LAMBERT JJ: Neuroactive steroids and inhibitory neurotransmission: mechanisms of action and physiological relevance. Neuroscience 138: 821-829, 2006.

BOWLBY MR: Pregnenolone sulfate potentiation of N-methyl-D-aspartate receptor channels in hippocampal neurons. Mol Pharmacol 43: 813-819, 1993.

BULLOCK AE, CLARK AL, GRADY SR, ROBINSON SF, SLOBE BS, MARKS MJ, COLLINS AC: Neurosteroids modulate nicotinic receptor function in mouse striatal and thalamic synaptosomes. $J$ Neurochem 68: 24122423, 1997.

CECCON M, RUMBAUGH G, VICINI S: Distinct effect of pregnenolone sulfate on NMDA receptor subtypes. Neuropharmacology 40: 491-500, 2001.

CORPECHOT C, ROBEL P, AXELSON M, SJOVALL J, BAULIEU EE: Characterization and measurement of dehydroepiandrosterone sulfate in rat brain. Proc Natl Acad Sci USA 78: 4704-4707, 1981.

DONG Y, FU Y-M, SUN J-L, ZHU Y-H, SUN F-Y, ZHENG P: Neurosteroid enhances glutamate release in rat prelimbic cortex via activation of alpha1-adrenergic and sigmal receptors. Cell Mol Life Sci 62: 1003-1014, 2005.

FLOOD JF, ROBERTS E: Dehydroepiandrosterone sulfate improves memory in aging mice. Brain Res 448: 178-181, 1988.

GASIOR M, CARTER RB, WITKIN JM: Neuroactive steroids: potential therapeutic use in neurological and psychiatric disorders. Trends Pharmacol Sci 20: 107-112, 1999.

GROBIN AC, ROTH RH, DEUTCH AY: Regulation of the prefrontal cortical dopamine system by the neuroactive steroid 3a,21-dihydroxy-5a-pregnane-20-one. Brain Res 578: 351-356, 1992.

HARRISON NL, SIMMONDS MA: Modulation of the GABA receptor complex by a steroid anaesthetic. Brain Res 323: 287-292, 1984.

HERD MB, BELELLI D, LAMBERT JJ: Neurosteroid modulation of synaptic and extrasynaptic GABA(A) receptors. Pharmacol Ther 116: 20-34, 2007.

HIGE T, FUJIYOSHI Y, TAKAHASHI T: Neurosteroid pregnenolone sulfate enhances glutamatergic synaptic transmission by facilitating presynaptic calcium currents at the calyx of Held of immature rats. Eur J Neurosci 24: 1955-1966, 2006.

HORAK M, VLCEK K, CHODOUNSKA H, VYKLICKY L Jr: Subtype-dependence of N-methyl-D-aspartate receptor modulation by pregnenolone sulfate. Neuroscience 137: 93-102, 2006.

HORAK M, VLCEK K, PETROVIC M, CHODOUNSKA H, VYKLICKY L Jr: Molecular mechanism of pregnenolone sulfate action at NR1/NR2B receptors. J Neurosci 24: 10318-10325, 2004.

HOSIE AM, WILKINS ME, SMART TG: Neurosteroid binding sites on GABA receptors. Pharmacol Ther 116: 7-19, 2007.

CHEN L, SOKABE M: Presynaptic Modulation of synaptic transmission by pregnenolone sulfate as studied by optical recordings. J Neurophysiol 94: 4131-4144, 2005.

CHEN L, MIYAMOTO Y, FURUYA K, MORI N, SOKABE M: PREGS induces LTP in the hippocampal dentate gyrus of adult rats via the tyrosine phosphorylation of NR2B coupled to ERK/CREB signaling. J Neurophysiol 98: 1538-1548, 2007.

CHEN L, MIYAMOTO Y, FURUYA K, DAI XN, MORI N, SOKABE M: Chronic DHEAS administration facilitates hippocampal long-term potentiation via an amplification of Src-dependent NMDA receptor signaling. Neuropharmacology 51: 659-670, 2006. 
JANG MK, MIERKE DF, RUSSEK SJ, FARB DH: A steroid modulatory domain on NR2B controls N-methyl-Daspartate receptor proton sensitivity. Proc Natl Acad Sci USA 101: 8198-8203, 2004.

JOHANSSON T, FRANDBERG PA, NYBERG F, LE GREVES P: Molecular mechanisms for nanomolar concentrations of neurosteroids at NR1/NR2B receptors. J Pharmacol Exp Ther 324: 759-768, 2008.

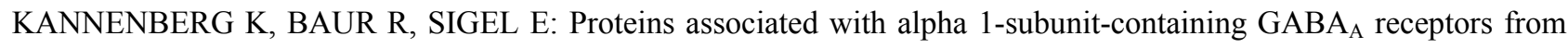
bovine brain. J Neurochem 68: 1352-1360, 1997.

LI Z, ZHOU R, CUI S, XIE G, CAI W, SOKABE M, CHEN L: Dehydroepiandrosterone sulfate prevents ischemiainduced impairment of long-term potentiation in rat hippocampal CA1 by up-regulating tyrosine phosphorylation of NMDA receptor. Neuropharmacology 51: 958-966, 2006.

MALAYEV A, GIBBS TT, FARB DH: Inhibition of the NMDA response by pregnenolone sulphate reveals subtype selective modulation of NMDA receptors by sulphated steroids. Br J Pharmacol 135: 901-909, 2002.

MAMELI M, CARTA M, PARTRIDGE LD, VALENZUELA CF: Neurosteroid-induced plasticity of immature synapses via retrograde modulation of presynaptic NMDA receptors. J Neurosci 25: 2285-2294, 2005.

MCEWEN BS: Non-genomic and genomic effects of steroids on neural activity. Trends Pharmacol Sci 12: 141-147, 1991.

MEYER DA, CARTA M, PARTRIDGE LD, COVEY DF, VALENZUELA CF: Neurosteroids enhance spontaneous glutamate release in hippocampal neurons. J Biol Chem 277: 28725-28732, 2002.

MORROW AL: Recent developments in the significance and therapeutic relevance of neuroactive steroids. Pharmacol Ther 116: 1-6, 2007.

NASMAN B, OLSSON T, BACKSTROM T, ERIKSSON S, GRANKVIST K, VIITANEN M, BUCHT G: Serum dehydroepiandrosterone sulfate in Alzheimer's disease and in multi-infarct dementia. Biol Psychiatry 30: 684690, 1991.

PARK-CHUNG M, WU FS, FARB DH: 3 alpha-hydroxy-5 beta-pregnan-20-one sulfate: a negative modulator of the NMDA-induced current in cultured neurons. Mol Pharmacol 46: 146-150, 1994.

PARK-CHUNG M, MALAYEV A, PURDY RH, GIBBS TT, FARB DH: Sulfated and unsulfated steroids modulate gamma-aminobutyric acid A receptor function through distinct sites. Brain Res 830: 72-87, 1999.

PARK-CHUNG M, WU FS, PURDY RH, MALAYEV AA, GIBBS TT, FARB DH: Distinct sites for inverse modulation of N-methyl-D-aspartate receptors by sulfated steroids. Mol Pharmacol 52: 1113-1123, 1997.

PARTRIDGE LD, VALENZUELA CF: Neurosteroid-induced enhancement of glutamate transmission in rat hippocampal slices. Neurosci Lett 301: 103-106, 2001.

PETROVIC M, SEDLACEK M, HORAK M, CHODOUNSKA H, VYKLICKY L Jr: 20-oxo-5beta-pregnan-3alpha-yl sulfate is a use-dependent NMDA receptor inhibitor. $J$ Neurosci 25: 8439-8450, 2005.

RUPPRECHT R, HOLSBOER F: Neuroactive steroids: mechanisms of action and neuropsychopharmacological perspectives. Trends Neurosci 22: 410-416, 1999.

SALTER MW, KALIA LV: Src kinases: a hub for NMDA receptor regulation. Nat Rev Neurosci 5: 317-328, 2004

SELYE H: Anesthetic effect of steroid hormones. Proc Soc Exp Biol Med 46: 116-121, 1941.

SHIRAKAWA H, KATSUKI H, KUME T, KANEKO S, AKAIKE A: Pregnenolone sulphate attenuates AMPA cytotoxicity on rat cortical neurons. Eur J Neurosci 21: 2329-2335, 2005.

SPIVAK V, LIN A, BEEBE P, STOLL L, GENTILE L: Identification of a neurosteroid binding site contained within the GluR2-S1S2 domain. Lipids 39: 811-819, 2004.

VALLEE M, MAYO W, DARNAUDERY M, CORPECHOT C, YOUNG J, KOEHL M, LE MOAL M, BAULIEU EE, ROBEL P, SIMON H: Neurosteroids: deficient cognitive performance in aged rats depends on low pregnenolone sulfate levels in the hippocampus. Proc Natl Acad Sci USA 94: 14865-14870, 1997.

WEAVER CE, LAND MB, PURDY RH, RICHARDS KG, GIBBS TT, FARB DH: Geometry and charge determine pharmacological effects of steroids on N-methyl-D-aspartate receptor-induced $\mathrm{Ca}^{2+}$ accumulation and cell death. J Pharmacol Exp Ther 293: 747-754, 2000.

WU FS, GIBBS TT, FARB DH: Inverse modulation of gamma-aminobutyric acid- and glycine-induced currents by progesterone. Mol Pharmacol 37: 597-602, 1990. 
WU FS, GIBBS TT, FARB DH: Pregnenolone sulfate: a positive allosteric modulator at the N-methyl-D-aspartate receptor. Mol Pharmacol 40: 333-336, 1991.

YAGHOUBI N, MALAYEV A, RUSSEK SJ, GIBBS TT, FARB DH: Neurosteroid modulation of recombinant ionotropic glutamate receptors. Brain Res 803: 153-160, 1998. 